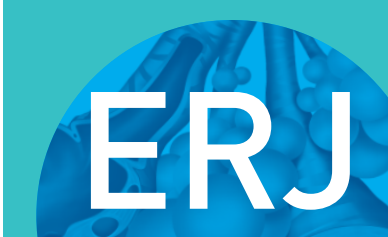

open research

\title{
Prognostic significance of pulmonary function tests in dyskeratosis congenita, a telomere biology disorder
}

\author{
Neelam Giri ${ }^{1}$, Sandhiya Ravichandran ${ }^{1}$, Youjin Wang ${ }^{1}$, Shahinaz M. Gadalla ${ }^{1}$, \\ Blanche P. Alter ${ }^{1}$, Joseph Fontana ${ }^{2,3}$ and Sharon A. Savage (10) ${ }^{1,3}$
}

Affiliations: ${ }^{1}$ Clinical Genetics Branch, Division of Cancer Epidemiology and Genetics, National Cancer Institute, National Institutes of Health, Bethesda, MD, USA. ${ }^{2}$ National Heart, Lung and Blood Institute, National Institutes of Health, Bethesda, MD, USA. ${ }^{3}$ These authors contributed equally.

Correspondence: Sharon A. Savage, Clinical Genetics Branch, Division of Cancer Epidemiology and Genetics, National Cancer Institute, 9609 Medical Center Drive, Bethesda, MD 20892-9772, USA.

E-mail: savageshamail.nih.gov

ABSTRACT Pulmonary fibrosis and pulmonary arteriovenous malformations are known manifestations of dyskeratosis congenita (DC), a telomere biology disorder (TBD) and inherited bone marrow failure syndrome caused by germline mutations in telomere maintenance genes resulting in very short telomeres. Baseline pulmonary function tests (PFTs) and long-term clinical outcomes have not been thoroughly studied in DC/TBDs.

In this retrospective study, 43 patients with DC and 67 unaffected relatives underwent baseline PFTs and were followed for a median of 8 years (range 1-14). Logistic regression and competing risk models were used to compare PFT results in relation to clinical and genetic characteristics, and patient outcomes.

Restrictive abnormalities on spirometry and moderate-to-severe reduction in diffusing capacity of the lung for carbon monoxide were significantly more frequent in patients with DC than relatives (42\% versus $12 \% ; \mathrm{p}=0.008)$. The cumulative incidence of pulmonary disease by age 20 years was $55 \%$ in patients with DC with baseline PFT abnormalities compared with $17 \%$ in those with normal PFTs $(p=0.02)$. None of the relatives developed pulmonary disease. X-linked recessive, autosomal recessive inheritance or heterozygous TINF2 variants were associated with early-onset pulmonary disease that mainly developed after haematopoietic cell transplantation (HCT). Overall, seven of 14 patients developed pulmonary disease post-HCT at a median of 4.7 years (range $0.7-12$ ). The cumulative incidence of pulmonary fibrosis in patients with heterozygous non-TINF2 pathogenic variants was $70 \%$ by age 60 years.

Baseline PFT abnormalities are common in patients with DC and associated with progression to significant pulmonary disease. Prospective studies are warranted to facilitate clinical trial development for patients with DC and related TBDs.

@ERSpublications

About $40 \%$ of patients with dyskeratosis congenita, a telomere biology disorder, have abnormal pulmonary function tests and progress to life-threatening pulmonary disease (PD). Prospective therapeutic studies of PD in these disorders are urgently needed. http://bit.ly/2HBSNCO

Cite this article as: Giri N, Ravichandran S, Wang Y, et al. Prognostic significance of pulmonary function tests in dyskeratosis congenita, a telomere biology disorder. ERJ Open Res 2019; 5: 002092019 [https://doi.org/10.1183/23120541.00209-2019].

This article has supplementary material available from openres.ersjournals.com

De-identified individual patient data will be available after completion of institutional review board-approved data transfer agreements between collaborating institutions.

Received: 19 Aug 2019 | Accepted: 28 Aug 2019

The content of this work is not subject to copyright. Design and branding are copyright @ERS 2019. This article is open access and distributed under the terms of the Creative Commons Attribution Non-Commercial Licence 4.0. 


\section{Introduction}

Dyskeratosis congenita (DC) is a telomere biology disorder (TBD) with a spectrum of associated medical complications including bone marrow failure (BMF), liver fibrosis, pulmonary fibrosis (PF), pulmonary arteriovenous malformations (PAVMs), and high cancer risk [1-4]. DC is clinically diagnosed by the classic triad of oral leukoplakia, abnormal skin pigmentation and nail dysplasia, but the appearance and age at onset of these features are highly variable [5]. The clinical spectrum of DC-related TBDs include Hoyeraal-Hreidarsson syndrome $(\mathrm{HH})$, which has features of DC plus cerebellar hypoplasia, immunodeficiency and intrauterine growth restriction (IUGR), and Revesz syndrome (RS), which is associated with bilateral exudative retinopathy, IUGR, and cerebral calcifications [6-8].

The clinical manifestations of TBDs are broad, due to different inheritance modes and variable genetic penetrance and expressivity. Pathogenic germline variants in dyskerin (DKC1) cause X-linked recessive (XLR) disease. TERT, RTEL1, ACD, and PARN are associated with both autosomal dominant (AD) and autosomal recessive (AR) disease. NOP10, NHP2, CTC1, STN1 and POT1 result in AR DC. AD disease is associated with TINF2, TERC and NAF1. TINF2 mutations are often de novo in the proband. All patients with DC and related TBDs have very short telomeres for their age; the shortest telomeres are in those presenting early in childhood with more symptoms and XLR, AR or TINF2 DC $[1,2,9]$.

Sporadic and familial PF associated with AD inheritance of pathogenic variants in TERT, TERC, RTEL1, $P A R N$ or NAF1 comprise the older-age-at-onset end of the TBD clinical spectrum, as they usually develop in the fifth to sixth decade of life [10-14]. The interstitial lung abnormalities seen on computed tomography (CT) scans in these patients often show a pattern consistent with usual interstitial pneumonia (UIP), but atypical patterns have been reported [15]. PF in younger patients with DC has been described after haematopoietic cell transplantation (HCT) [16]. PAVMs are being increasingly recognised in patients with DC who may or may not have received an HCT, and may occur alone or in the setting of hepatopulmonary syndrome $[17,18]$.

In this study, we determined baseline pulmonary function in 43 patients with DC/TBD and 67 unaffected relatives and correlated the findings with the underlying genetics and clinical outcomes to better understand the manifestations of pulmonary disease in TBDs.

\section{Methods}

\section{Study design and participants}

This is a retrospective and prospective observational study of individuals who were participants in the National Cancer Institute's (NCI) Institutional Review Board-approved longitudinal cohort study of inherited BMF syndromes (ClinicalTrials.gov identifier: NCT00027274; https://marrowfailure.cancer.gov) [3, 19]. All participants, or their guardians, provided written informed consent at enrolment in accordance with Health and Human Services regulation 45 CFR 46.

Pulmonary function tests (PFTs) were performed by all patients with DC and their unaffected first-degree relatives who were 6 years of age or older when evaluated at the National Institutes of Health $(\mathrm{NIH})$ Clinical Center in Bethesda, MD between January 2002 until December 2015.The participants were followed through December 31, 2016.

The clinical diagnosis of DC was based on the presence of two mucocutaneous triad features or one triad feature plus BMF [20], and/or very short telomeres $(<1$ st percentile for age $)$ in peripheral blood lymphocyte subsets by flow cytometry with fluorescent in situ hybridisation (flow FISH) [21], and confirmed by identification of germline pathogenic variants in DC/TBD genes in the majority of patients. The unaffected relatives had a normal peripheral blood telomere length and no disease-associated pathogenic variants (in families with a known gene defect) or carried one pathogenic variant associated with AR disease in the proband of their family.

\section{PFTs and outcome assessment}

All participants underwent PFTs at the pulmonary function laboratory at the NIH Clinical Center according to the American Thoracic Society/European Respiratory Society (ATS/ERS) Task Force standardisation of lung function testing $[22,23]$. Spirometry, lung volumes (using body plethysmography or nitrogen washout technique), and single-breath diffusing capacity of the lung for carbon monoxide $\left(D_{\mathrm{LCO}}\right)$ were obtained using the CareFusion $\mathrm{V}_{\max }$ Encore System (version 28-4). PFT data were merged with each subject's demographic, laboratory and clinical details in an Excel file.

Each PFT parameter was corrected for age, sex, height and ethnicity using published reference equations as per the ATS/ERS Task force recommendations [24]. $D_{\text {LCO }}$ was corrected for haemoglobin. Forced vital capacity (FVC), forced expiratory volume in $1 \mathrm{~s}\left(\mathrm{FEV}_{1}\right), \mathrm{FEV}_{1} / \mathrm{FVC}$ ratio and total lung capacity (TLC) were used to interpret lung function using the ATS/ERS Task Force algorithm [24]. All PFT results were 
reviewed and interpreted by a pulmonologist. A PFT value $<5$ th percentile of the predicted normal value for age, sex, height and ethnicity was considered abnormal and was stated as less than the lower limit of normal $(<L L N)$. Classification and grading of obstructive, restrictive or mixed abnormalities were based on the ATS/ERS guidelines [24]. A significant PFT abnormality was defined as abnormal spirometry and/or moderate or severe reduction in $D_{\mathrm{LCO}}$.

Individuals with history or clinical findings suggestive of lung involvement at the time of evaluation, or those who became symptomatic later, had further testing with high-resolution CT (HRCT) of lungs plus or minus transthoracic contrast echocardiography (TTCE) with agitated saline bubble, as clinically indicated. HRCT was only done if the patient was symptomatic in order to limit unnecessary medical radiation exposure. HRCTs were reviewed by expert radiologists and pulmonologists. PF was diagnosed by characteristic interstitial lung findings on HRCT [15]. PAVMs were diagnosed by a delay in the appearance of microbubbles in the left heart by more than three beats on TTCE after appearance in the right heart, indicating a right-to-left shunt [25].

\section{Analysis}

The study schema is detailed in figure 1. The characteristics of patients and unaffected relatives were compared by a Mann-Whitney U-test for continuous variables and a Fisher's exact test for categorical variables. The PFT results of patients with AR, XLR and AD TINF2 DC were compared with those of AD non-TINF2 DC, due to known differences in their disease manifestations, severity and age at diagnosis [1, 9, 26]. The PFT results of unaffected heterozygous carrier relatives with variants in RTEL1, TERT and $P A R N$ were also compared with all other relatives because PF has been reported in individuals heterozygous for pathogenic variants in these genes $[14,27,28]$.

We used logistic regression models and calculated the odds ratios (ORs) and 95\% confidence intervals (CIs) of PFT abnormalities in relation to patient characteristics. Factors evaluated included DC inheritance (AR/XLR/TINF2 versus AD non-TINF2), DC mucocutaneous triad (0-1 versus 2-3 features), smoking history, sex, age at PFT, lymphocyte telomere length Z-score, and degree of BMF (severe versus none/ moderate as described previously [21]). We also evaluated the association of baseline PFT abnormalities with subsequent development of clinical pulmonary disease. Patients who received HCT prior to the baseline PFT study were excluded from analyses involving phenotypic characteristics and baseline PFT data but were included in analyses evaluating the association of HCT with pulmonary disease. We used the cumulative incidence estimator to calculate the cumulative incidence of pulmonary disease considering death from other causes as a competing risk. Follow-up started with age at PFT and ended at the earliest incidence of pulmonary disease, death or end of follow-up. We determined the association of pulmonary disease with HCT, and outcomes according to inheritance patterns with censoring at the first adverse event (HCT, pulmonary disease or death). Follow-up for the adverse event analysis started at birth.

Statistical analyses were performed using Stata 14.2 (StataCorp, College Station, TX, USA), SAS (SAS Institute, Cary, NC, USA), and R (version 3.3.0; R Foundation for Statistical Computing, Vienna, Austria). All statistical tests were two-sided with statistical significance defined as p-values $<0.05$.

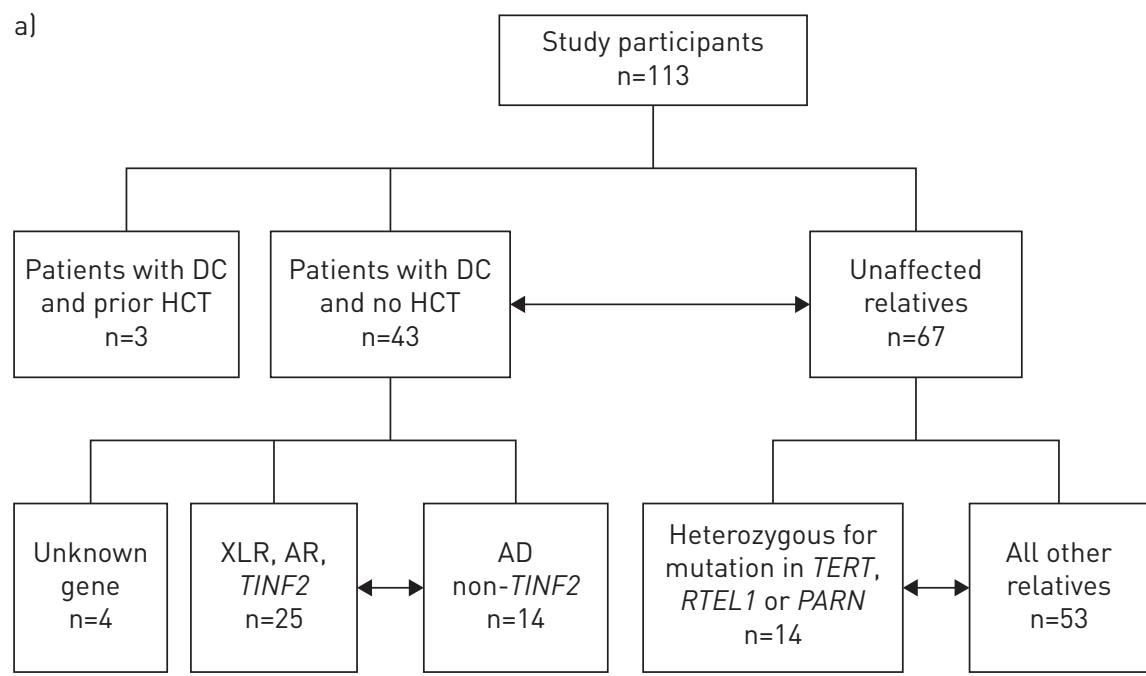

b) i) Pulmonary disease in relation to baseline PFTs

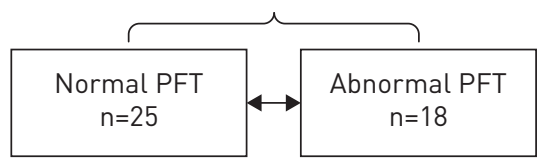

ii) Pulmonary disease in relation to HCT

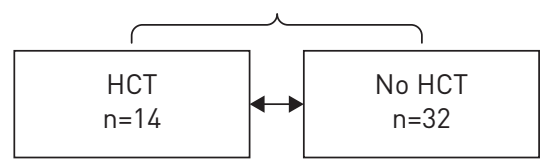

iii) Outcomes according to DC inheritance

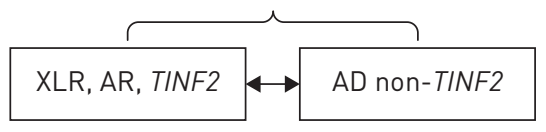

FIGURE 1 Study schema indicating the comparison groups. a) Analyses of pulmonary function tests (PFTs) and groups. b) Analyses of patient outcomes in relation to PFT. DC: dyskeratosis congenita; HCT: haematopoietic cell transplantation; XLR: X-linked recessive; AR: autosomal recessive; $A D$ : autosomal dominant. 


\section{Results}

\section{Participant characteristics}

The participant demographics are described in table 1. Patients with DC were younger $(\mathrm{p}=0.0001)$, and more likely to be male $(\mathrm{p}=0.001)$ than their unaffected relatives. Patients with AR, XLR, and TINF2 DC developed disease features earlier, and were younger compared with AD non-TINF2 DC at evaluation $(\mathrm{p}<0.0001$ and $\mathrm{p}=0.002$, respectively), had more complex DC-related clinical findings $(\mathrm{p}<0.05)$, and significantly lower telomere length Z-scores $(\mathrm{p}=0.0007)$. Heterozygous carrier relatives with variants in RTEL1, TERT, and PARN ( $\mathrm{n}=14)$ had similar demographics and telomere length Z-scores as the other 53 relatives.

\section{PFT results}

Patients

A total of 12 of 43 patients (28\%) with DC had baseline PFT abnormalities according to spirometry and lung volume studies (table 2 and table S1). Overall, two patients had moderate or severe obstructive patterns with $\mathrm{FEV}_{1}$ at $68 \%$ and $48 \%$ of predicted, respectively, and 10 patients had a restrictive pattern with FVC and/or TLC below $95 \%$ of predicted. A total of 23 patients had mild $D_{\text {LCO }}$ changes $\left(D_{\text {LCO }}<\right.$ LLN-60\%), and 13 had moderate $\left(D_{\text {LCO }}<60-40 \%\right)$ or severe diffusion abnormalities $\left(D_{\text {LCO }}\right.$ $<40 \%)$. Moderate or severe $D_{\mathrm{LCO}}$ abnormalities were associated with an abnormal spirometry pattern (OR $7.2,95 \%$ CI $1.5-33 ; \mathrm{p}=0.019$ ) that was mainly restrictive but mild $D_{\text {LCO }}$ changes were not (table S2). Overall, 18 patients (42\%) had significant PFT abnormalities with either an obstructive or a restrictive pattern on spirometry and/or moderate-to-severe diffusion defect on $D_{\text {LCO }}$. The PFT results of patients with AR, XLR and TINF2 DC were similar to those with AD non-TINF2 DC.

\section{Unaffected relatives}

Overall, 11 of 67 relatives (16\%) had abnormal spirometry findings (table 2); six relatives had a mild obstructive pattern with $\mathrm{FEV}_{1}$ ranging from $70 \%$ to $84 \%$ of predicted. One chronic heavy smoker had a moderately severe obstructive pattern with $\mathrm{FEV}_{1}$ at $55 \%$ of predicted, and four had a mild restrictive pattern. In total, 33 relatives had a borderline-to-mild decrease in $D_{\text {LCO }}$ and five had moderate $D_{\text {LCO }}$ abnormalities (43\% to $59 \%$ predicted). In all, 12 relatives (18\%) had an abnormal spirometry pattern and/ or moderately reduced $D_{\mathrm{LCO}}$. The PFTs of relatives with heterozygous variants in RTEL1, TERT or PARN and all other relatives were similar (table 2).

When comparing patients with relatives, there was no difference in the frequency of obstructive abnormalities between patients with DC and their relatives (5\% versus $10 \% ; \mathrm{p}=0.47$ ), but restrictive abnormalities were significantly more prevalent in the patients $(23 \%$ versus $6 \%$; $=0.016)$ (table 2$)$. A significantly higher proportion of patients had a moderate or severe reduction in $D_{\text {LCO }}$ compared with relatives $(29 \%$ versus $7 \%$; $\mathrm{p}=0.003)$. Overall, abnormal spirometry at baseline and/or moderate or severe $D_{\mathrm{LCO}}$ abnormalities were more frequent in patients with DC than in their relatives ( $42 \%$ versus $12 \%$; $\mathrm{p}=0.008$ ).

\section{Association of PFTs with clinical features}

Significant associations from univariate analysis are presented in table S3. In multivariable models, the presence of a PFT abnormality was associated with severe BMF (OR 17; 95\% CI 1.8-165; p=0.01), and with a history of smoking (OR $70.85 ; 95 \%$ CI 1.8 to $>999$; $\mathrm{p}=0.02$ ) but not with any other feature tested (table 3).

\section{Baseline PFT and subsequent pulmonary disease}

Overall, 10 of the 43 patients with DC (23\%) developed symptomatic pulmonary disease at a median of 5 years (range 0-10) from the baseline PFT studies; six had PF identified on HRCTs (table 4), three had evidence of PAVMs on TTCE in addition to PF on HRCT, and one had AVMs without fibrosis (table 4). The HRCT pattern was consistent with UIP in six patients (figure 2 shows representative HRCT scans of NCI-6-1 with progressive disease over time). Overall, two patients had HRCT findings consistent with nonspecific interstitial pneumonitis (NSIP), and one had hypersensitive pneumonitis (table 4).

Categorisation by baseline PFTs showed that eight of 18 patients with an abnormal baseline PFTs developed pulmonary disease compared with two of 25 patients with a normal baseline PFTs $(p=0.009)$. Of note, one patient (NCI-329-1) with an abnormal baseline PFT had a diagnosis of PF for 4 years prior to the study and two patients (NCI-114-1 and NCI-350-1) were diagnosed with PF by HRCT at the time of baseline evaluations due to symptoms of exertional dyspnoea and an intermittent dry cough (table 4). The cumulative incidence of subsequent pulmonary disease in those free of pulmonary events at baseline was 55\% (95\% CI 28-100\%) by age 20 years in patients with abnormal baseline PFTs versus $17 \%$ (95\% CI $3-100 \%$ ) in those with normal PFTs (figure 3; $\mathrm{p}=0.02$ ). None of the 67 relatives had pulmonary disease at a median follow-up of 8 years (range 1-14). 
TABLE 1 Characteristics of study participants

\begin{tabular}{|c|c|c|c|c|c|c|c|c|}
\hline & \multicolumn{4}{|c|}{ Patients with DC } & \multicolumn{3}{|c|}{ Unaffected relatives } & \multirow{2}{*}{$\begin{array}{c}\text { Patients versus relatives } \\
\text { p-value }\end{array}$} \\
\hline & All & XLR, AR, TINF2" & AD non-TINF2 ${ }^{\#}$ & p-value & All & $\begin{array}{c}\text { Carriers of RTEL1, } \\
\text { TERT or PARN }\end{array}$ & All others & \\
\hline Participants & 43 & 25 & 14 & & 67 & 14 & 53 & \\
\hline Age at diagnosis years & $13(1-65)$ & $11(1-43)$ & $32(12-65)$ & $<0.0001$ & & & & \\
\hline Age at study years & $21(6-69)$ & $18(6-42)$ & $35(12-69)$ & 0.002 & $46(10-60)$ & $46(10-60)$ & $36(7-64)$ & 0.0001 \\
\hline Male/female & $31 / 12$ & $21 / 4$ & $7 / 7$ & 0.03 & $25 / 42$ & $6 / 8$ & $19 / 34$ & 0.001 \\
\hline Smoker & $7(15 \%)$ & 3 & 4 & 0.2 & $10(15 \%)$ & $3(21 \%)$ & $7(13 \%)$ & 0.8 \\
\hline \multicolumn{9}{|l|}{ Ethnicity } \\
\hline Caucasian & 40 & 24 & 12 & & 63 & 14 & 49 & 0.7 \\
\hline African & 2 & 1 & 1 & & 0 & 0 & 0 & \\
\hline Hispanic & 0 & 0 & 0 & & 1 & 0 & 1 & \\
\hline Asian & 1 & 0 & 1 & & 3 & 0 & 3 & \\
\hline Microcephaly & 11 & 11 & 0 & 0.003 & 0 & 0 & 0 & \\
\hline $\mathrm{HH} / \mathrm{RS}$ & 8 & 8 & 0 & 0.03 & 0 & 0 & 0 & \\
\hline \multicolumn{9}{|l|}{ DC triad features ${ }^{\pi}$} \\
\hline $0-1$ & 20 & 8 & 11 & 0.008 & 63 & 14 & 53 & \\
\hline$\geqslant 2$ & 23 & 17 & 3 & & 0 & 0 & 0 & \\
\hline \multicolumn{9}{|l|}{ Bone marrow failure ${ }^{+}$} \\
\hline None & 12 & 7 & 5 & 0.2 & 0 & 0 & 0 & \\
\hline Moderate & 13 & 4 & 5 & & & & & \\
\hline Severe & 18 & 14 & 4 & & & & & \\
\hline Telomere length Z-score & -3.9 & $-4.5(-1.3--6.7)$ & $-3.1(-1.1--5.5)$ & 0.0007 & $-0.9(-1.8--4.2)$ & $-1.9(-0.3--1.9)$ & $-0.7(-0.7--4.2)$ & $<10^{-9}$ \\
\hline \multicolumn{9}{|l|}{ DC gene (inheritance) } \\
\hline DKC1 (XLR) & 7 & 7 & 0 & & 7 & 0 & 7 & \\
\hline RTEL 1 (AR or AD) & 7 & 6 & 1 & & 8 & 8 & 0 & \\
\hline PARN (AR) & 3 & 3 & 0 & & 5 & 5 & 0 & \\
\hline WRAP53 (AR) & 0 & 0 & 0 & & 3 & 0 & 3 & \\
\hline$A C D(\mathrm{AR})$ & 0 & 0 & 0 & & 2 & 0 & 2 & \\
\hline TERT (AR or AD) & 6 & 1 & 5 & & 1 & 1 & 0 & \\
\hline TINF2 (AD) & 8 & 8 & 0 & & 0 & 0 & 0 & \\
\hline TERC (AD) & 8 & 0 & 8 & & 0 & 0 & 0 & \\
\hline Unknown & 4 & 0 & 0 & & 15 & 0 & 15 & \\
\hline Negative & 0 & & & & 26 & 0 & 26 & \\
\hline $\begin{array}{l}\text { Data are presented as } \\
\text { Hoyeraal-Hreidarsson syn } \\
\text { not identified in four patie } \\
\text { "severe" was cytopenia ne }\end{array}$ & $\begin{array}{l}\text { ian lrange } \\
\text { me; RS: R } \\
\text { १: oral le } \\
\text { ig treatme }\end{array}$ & $\begin{array}{l}\text { unless otherwise } \\
\text { sz syndrome. }{ }^{\#} \text { th } \\
\text { oplakia, dysplastic } \\
\text { Significant p-valu }\end{array}$ & $\begin{array}{l}\text { ted. DC: dyskera } \\
\text { number of patient } \\
\text { Is and abnormal } \\
(<0.05) \text { are in bold }\end{array}$ & $\begin{array}{l}\text { is cong } \\
\text { th } \mathrm{XLR} / \\
\text { pigmer }\end{array}$ & $\begin{array}{l}\text { ta; XLR: X-linked } \\
\text { ITINF2 and AD nor } \\
\text { tion; }{ }^{+}: \text {"moderate }\end{array}$ & $\begin{array}{l}\text { cessive; AR: auto } \\
\text { NF2 do not add up } \\
\text { as defined as sing }\end{array}$ & $\begin{array}{l}\text { nal recessive; } A D \\
\text { the total of } 43 \mathrm{bec} \\
\text { or multilineage cyt }\end{array}$ & $\begin{array}{l}\text { autosomal dominant; } \mathrm{HH} \text { : } \\
\text { se the causative gene was } \\
\text { enia not on treatment, and }\end{array}$ \\
\hline
\end{tabular}




\section{TABLE 2 Pulmonary function tests (PFTs) in study participants}

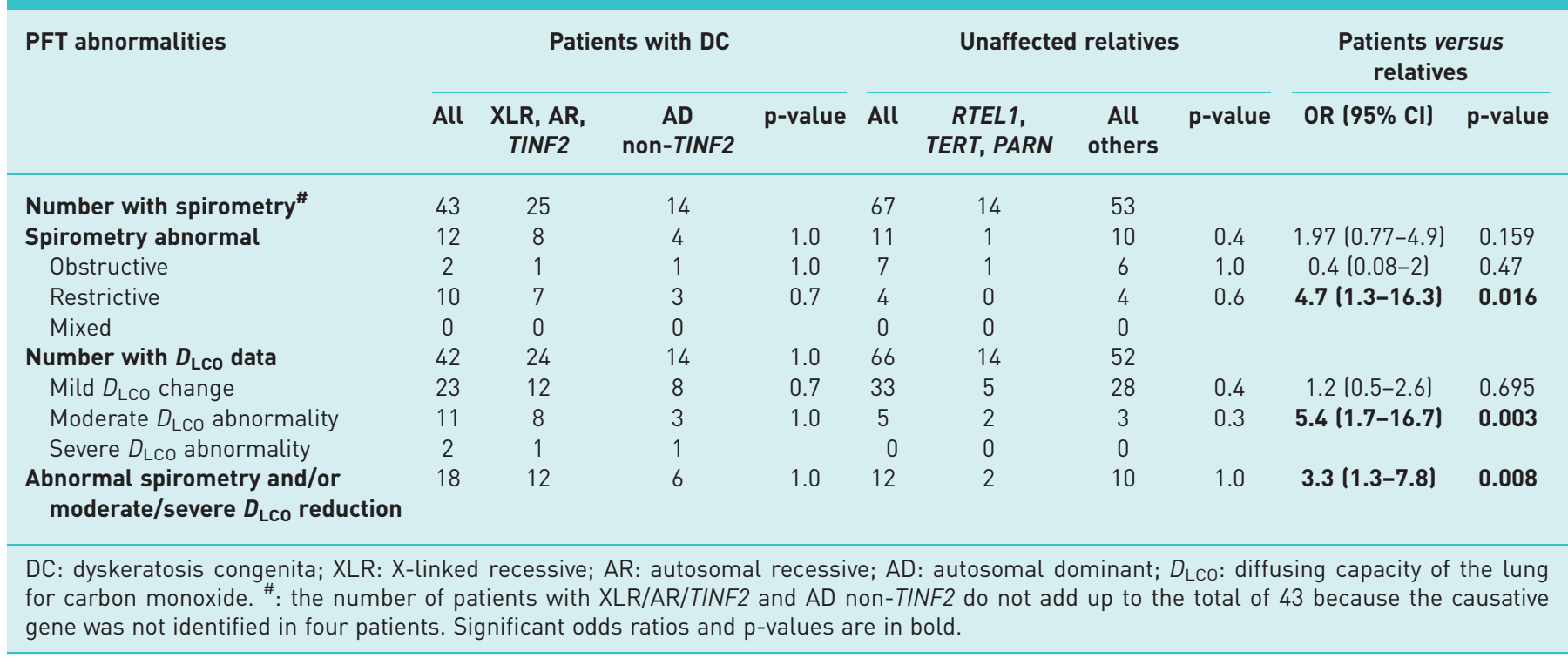

Pulmonary disease in relation to HCT

In total, 11 of 43 patients underwent HCT within 1-7 years (median 2 years) after baseline PFTs. The three additional patients who had undergone HCT prior to PFTs are included in the following analyses. Overall, seven of these 14 post-HCT patients developed symptomatic pulmonary disease at a median of 4.7 years (range 0.7-12) after the HCT (table S4). The median age at HCT was 12.9 years (range 3.2-29) and the median age at pulmonary disease was 15 years (range 11-22). Overall, four patients had PF alone, two had PF plus PAVMs, and one had AVM without PF (table 4). In contrast, five of 32 patients with DC who did not have HCT (16\%) became symptomatic with pulmonary disease at 21, 54, 56, 59 and 65 years of age; the patients $>50$ years old had PF, whereas the 21 -year-old patient had PF plus PAVMs. The risk of pulmonary disease was higher among those with than without HCT (OR 7.7; CI 1.7-33; $\mathrm{p}=0.027$ ). Additionally, pulmonary disease developed at younger ages in post-HCT patients $(\mathrm{p}=0.009)$, included both PF and PAVMs, and majority of these patients (12/14) had XLR/AR or TINF2 DC. The non-HCT patients mainly developed PF that occurred at older ages (table S4).

\section{Pulmonary disease and genetic aetiology}

In the competing risk analysis with censoring at the earliest event that included HCT, pulmonary disease or death, the first adverse event in patients with AR, XLR or TINF2 DC was HCT for severe BMF (12 patients) with a cumulative incidence of $50 \%$ (95\% CI 33-77\%) by age 30 years. Death occurred in two

TABLE 3 Factors associated with pulmonary function test abnormalities

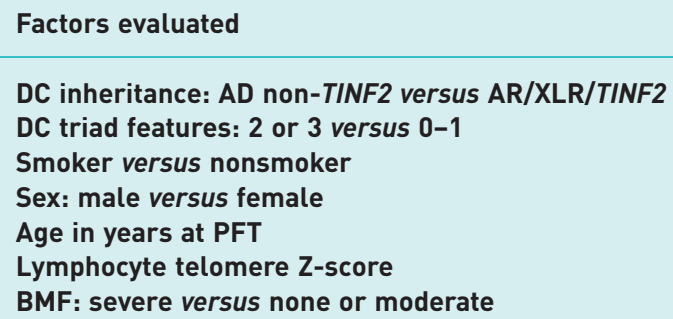

$\begin{array}{cc}\text { OR }(95 \% \text { CI) } & \text { p-value } \\ 0.04(<0.001-1.57) & 0.08 \\ 0.90(0.12-6.55) & 0.92 \\ 70.85(1.84->999.999) & \mathbf{0 . 0 2} \\ 0.25(0.02-2.70) & 0.25 \\ 1.11(0.99-1.24) & 0.07 \\ 0.63(0.20-1.94) & 0.42 \\ 17.36(1.82-165.30) & \mathbf{0 . 0 1}\end{array}$

The multivariable regression model used includes dyskeratosis congenita (DC) inheritance lautosomal recessive (AR)/X-linked recessive (XLR)/TINF2 versus autosomal dominant (AD) non-TINF2), DC triad (0-1 versus 2-3), smoking, sex, age at pulmonary function testing (PFT) (integer), lymphocyte telomere Z-score, and bone marrow failure (BMF) (severe versus none/moderate). Overall, 38 patients were included in the multivariable regression model; five patients were excluded (four with unknown gene status and one without telomere length Z-score datal. Significant p-values are in bold. 
TABLE 4 Features of patients with dyskeratosis congenita and pulmonary disease

\begin{tabular}{|c|c|c|c|c|c|c|c|c|c|c|c|c|}
\hline NCI UPN & Gene & $\begin{array}{l}\text { Age at } \\
\text { diagnosis } \\
\text { years }\end{array}$ & $\begin{array}{l}\text { Age } \\
\text { at PFT } \\
\text { years }\end{array}$ & $D_{\text {Lco }}$ & Spirometry & $\begin{array}{l}\text { Age } \\
\text { at } \mathrm{HCT} \\
\text { years }\end{array}$ & HCT regimen & $\begin{array}{l}\text { Age at } \\
\text { PD years }\end{array}$ & $\begin{array}{l}\text { Pulmonary } \\
\text { symptoms }\end{array}$ & HRCT scan lungs & AVM & Outcome \\
\hline $160-1$ & TINF2 & 3.6 & 6.6 & $65 \%$ & Restrictive & 9.5 & Cy/Flu/TBI & 12 & Dyspnoea, $\downarrow S_{\mathrm{O}_{2}}$ & $\begin{array}{l}\text { Bibasilar fibrosis progressed over } \\
2 \text { years with features of UIP }\end{array}$ & No & $\begin{array}{l}\text { Died from pulmonary } \\
\text { fibrosis, age } 14 \text { years }\end{array}$ \\
\hline 216-1 & AR-RTEL1 & 6 & 8.9 & $51 \%$ & Obstructive & 9.1 & $\mathrm{Cy} / \mathrm{Flu} / \mathrm{Bu}$ & 14 & $\begin{array}{l}\text { Dyspnoea, } \downarrow S_{\mathrm{O}_{2}} \\
\text { worse with } \\
\text { exercise }\end{array}$ & $\begin{array}{l}\text { Interstitial changes with } \\
\text { ground-glass opacities mainly in } \\
\text { apices c/w NSIP; } 2 \text { AVMs }\end{array}$ & $\begin{array}{l}\text { Yes, } \\
\text { large }\end{array}$ & $\begin{array}{l}\text { Pulmonary AVM coiled } \\
\text { at age } 17 \text { years; alive } \\
\text { age } 18 \text { years }\end{array}$ \\
\hline $145-1$ & TINF2 & 3 & 9.5 & $62 \%$ & Normal & 10.9 & $\mathrm{Cy} / \mathrm{Flu} / \mathrm{Bu}$ & 15 & Dyspnoea, $\downarrow \mathrm{S}_{\mathrm{O}_{2}}$ & Normal & $\begin{array}{l}\text { Yes, } \\
\text { liver }\end{array}$ & $\begin{array}{l}\text { Died from HPS, age } \\
16 \text { years }\end{array}$ \\
\hline 87-1 & $D K C 1$ & 3 & 10.6 & $49 \%$ & Restrictive & 16.2 & Cy/Flu/TBI & 17 & $\begin{array}{l}\text { Cough, air } \\
\text { hunger }\end{array}$ & $\begin{array}{c}\text { Patchy ground-glass opacities with } \\
\text { honeycombing c/w UIP }\end{array}$ & No & $\begin{array}{l}\text { Died from pulmonary } \\
\text { fibrosis, age } 18 \text { years }\end{array}$ \\
\hline 297-2 & AR-RTEL1 & 14 & 18.3 & $61 \%$ & Restrictive & 19.3 & Flu/C/TBI & 22 & Dyspnoea, $\downarrow \mathrm{S}_{\mathrm{O}_{2}}$ & $\begin{array}{c}\text { Numerous small micronodular } \\
\text { opacities c/w hypersensitive } \\
\text { pneumonitis; linear opacities c/w } \\
\text { mild interstitial fibrosis }\end{array}$ & $\begin{array}{l}\text { Yes, } \\
\text { portal }\end{array}$ & $\begin{array}{l}\text { Alive with pulmonary } \\
\text { symptoms, age } 23 \text { years }\end{array}$ \\
\hline $204-1^{\#}$ & TINF2 & 3 & 12.7 & $<40 \%$ & Restrictive & 4.2 & Cy/ATG & 11 & $\begin{array}{l}\text { Cough, air } \\
\text { hunger }\end{array}$ & $\begin{array}{l}\text { Multifocal areas of reticular and } \\
\text { ground-glass opacities with } \\
\text { honeycombing c/w UIP }\end{array}$ & No & $\begin{array}{l}\text { Lung transplant age } \\
13 \text { years; died from oral } \\
\text { cancer, age } 19 \text { years }\end{array}$ \\
\hline $231-1^{\#}$ & UK & 3 & 9.8 & $53 \%$ & Restrictive & 3.9 & Cy/Flu/TBI & 14 & $\begin{array}{l}\text { Cough, } \\
\text { dyspnoea, air } \\
\text { hunger }\end{array}$ & $\begin{array}{l}\text { Patchy diffuse ground-glass } \\
\text { opacities c/w NSIP pattern }\end{array}$ & No & $\begin{array}{l}\text { Died from pulmonary } \\
\text { fibrosis, age } 17 \text { years }\end{array}$ \\
\hline $291-1^{\pi}$ & PARN & 13 & 19.2 & $25 \%$ & Restrictive & & & 21 & Clubbing, $\downarrow \mathrm{S}_{2}$ & $\begin{array}{l}\text { Increased reticular markings with } \\
\text { architectural distortion in upper } \\
\text { lung zones suggestive of NSIP }\end{array}$ & $\begin{array}{l}\text { Yes, } \\
\text { portal }\end{array}$ & $\begin{array}{l}\text { Underwent } \mathrm{HCT} \text { at age } \\
22 \text { years; alive with } \\
\text { pulmonary symptoms, } \\
\text { age } 25 \text { years }\end{array}$ \\
\hline 6-1 & TERC & 28 & 44.6 & $88 \%$ & Restrictive & & & 54 & $\begin{array}{l}\text { Cough, } \\
\text { dyspnoea, } \downarrow S_{\mathrm{O}_{2}}\end{array}$ & $\begin{array}{c}\text { Peripheral interstitial and } \\
\text { ground-glass opacities with } \\
\text { honeycombing in bases bilaterally } \\
\text { c/w UIP }\end{array}$ & No & $\begin{array}{l}\text { Alive on supplemental } \\
\mathrm{O}_{2} \text {, age } 58 \text { years }\end{array}$ \\
\hline $114-1$ & TERC & 34 & 56.7 & $57 \%$ & Restrictive & & & 56.7 & $\begin{array}{l}\text { Dyspnoea on } \\
\text { exertion }\end{array}$ & $\begin{array}{l}\text { Progressive polygonal and reticular } \\
\text { opacities both lung bases and upper } \\
\text { lobes c/w UIP }\end{array}$ & & $\begin{array}{l}\text { Alive, has dyspnoea and } \\
\downarrow \mathrm{S}_{\mathrm{O}_{2}} \text { on exertion, age } \\
59 \text { years }\end{array}$ \\
\hline $350-1^{\pi}$ & TERC & 44 & 59.5 & $61 \%$ & Obstructive & & & 59.54 & $\begin{array}{l}\text { Cough, } \\
\text { dyspnoea, } \downarrow \mathrm{S}_{\mathrm{O}_{2}}\end{array}$ & $\begin{array}{l}\text { Decreased lung volume; both lower } \\
\text { lobes with increased interstitial } \\
\text { markings in the periphery with } \\
\text { areas of honeycombing (UIP and } \\
\text { NSIP pattern) }\end{array}$ & No & $\begin{array}{c}\text { Underwent HCT at age } \\
63 \text { years; died from HCT } \\
\text { complications }\end{array}$ \\
\hline $329-1$ & TERT & 65 & 69 & $34 \%$ & Restrictive & & & 65 & Dyspnoea, $\downarrow \mathrm{S}_{\mathrm{O}_{2}}$ & $\begin{array}{l}\text { Extensive areas of honeycombing } \\
\text { and peripheral fibrosis more } \\
\text { marked in lung bases c/w UIP }\end{array}$ & No & $\begin{array}{l}\text { Died from pulmonary } \\
\text { fibrosis, age } 69 \text { years }\end{array}$ \\
\hline
\end{tabular}



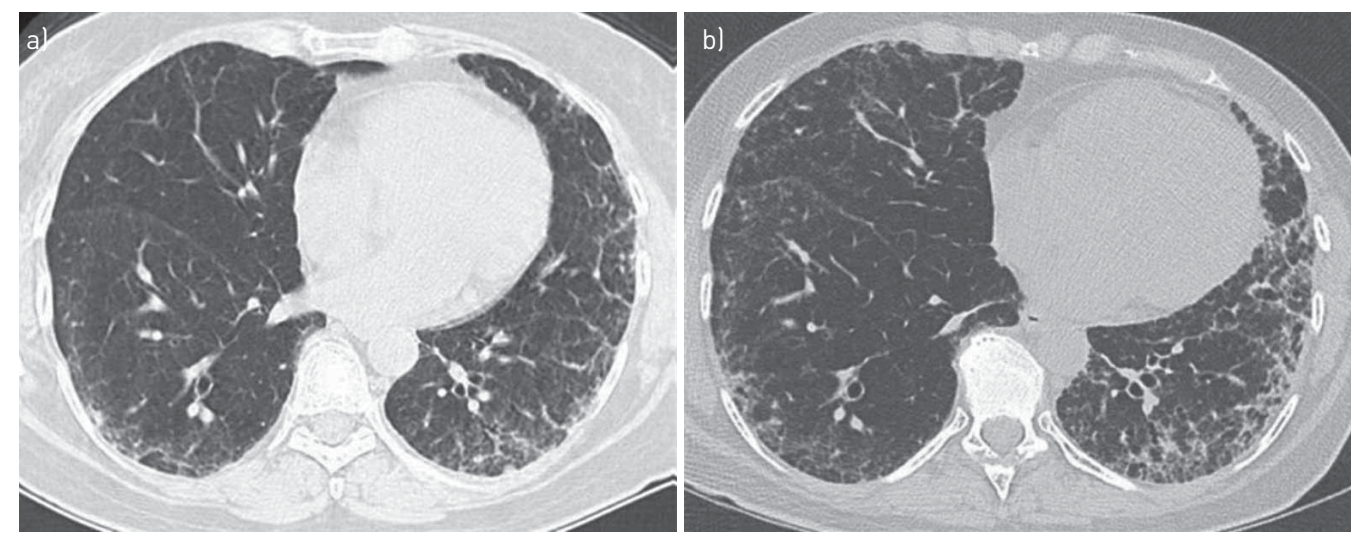

FIGURE 2 High-resolution computed tomography (CT) scan of the lungs (patient NCl-6-1). a) Peripheral interstitial and ground-glass opacities with early honeycombing in bases bilaterally consistent with usual interstitial pneumonia pattern of pulmonary fibrosis in a 54-year-old female with heterozygous TERC mutation and symptoms of dyspnoea on exertion, impaired flows and diffusion with diffusing capacity of the lung for carbon monoxide ( $\left.D_{\mathrm{LCO}}\right) 57 \%$ of predicted. b) The patient's symptoms had progressed 3 years later with dry cough, progressive dyspnoea, basal crackles and desaturation to $85 \%$ on 6 -minute walk test; restrictive ventilatory defect and $D_{\mathrm{LCO}}$ at $50 \%$. The CT scan shows an increase in peripheral subpleural fibrosis. The advanced fibrosis in the left lung is also slightly worsened.

patients (one from BMF-related complications at age 19 years and one from rectal adenocarcinoma at age 37 years), and PF plus PAVMs in one patient at age 20 years (figure 4a). However, six of the 12 patients with HCT as a first event, subsequently developed pulmonary disease at a median of 3 years after HCT (range $0.7-7$ ). In AD non-TINF2 DC, HCT was the earliest event in only one patient (age 20 years), whereas four patients developed PF with a cumulative incidence of $70 \%$ (95\% CI 39-100\%) by age 60 years (figure $4 \mathrm{~b}$ ). Regardless of the HCT status, clinically symptomatic pulmonary disease developed in $26 \%$ of patients with AR, XLR or TINF2 DC and in 29\% of patients with AD non-TINF2 DC (29\%) albeit across different age ranges (median age 15 years versus 58 years, respectively), different types (PF and/or PAVMs versus PF, respectively) and under different settings (post-HCT and no HCT, respectively).

\section{Outcome of patients with DC and pulmonary disease}

The clinical details and outcomes of patients with pulmonary disease are shown in table 4. One patient with severe hypoxaemia due to a large PAVM (NCI-216-1) underwent transcatheter coil embolisation at

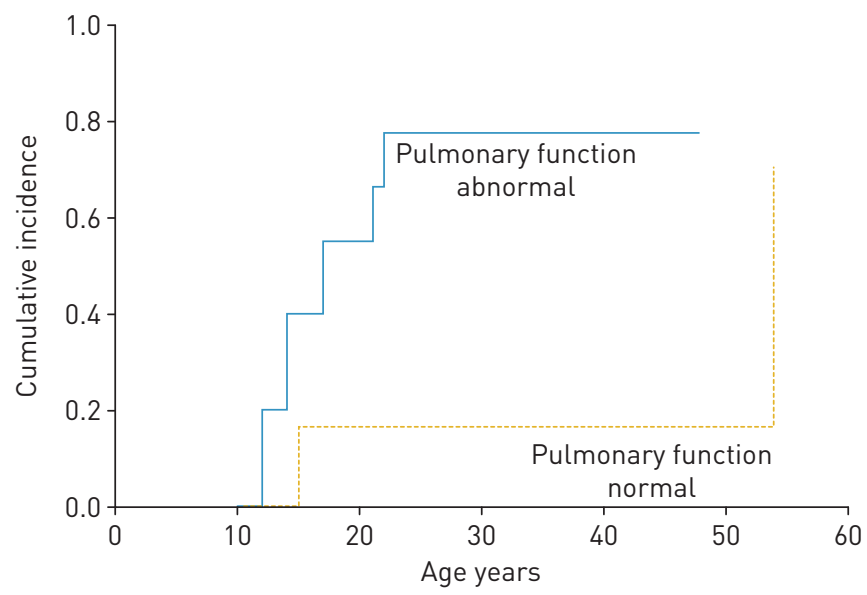

FIGURE 3 Cumulative incidence of pulmonary disease in patients with normal versus abnormal baseline pulmonary function tests (PFTs). The graph starts at the age at PFT and ends at the diagnosis of pulmonary disease, death or last follow-up. The three patients with incident pulmonary disease at the time of baseline PFT were excluded from the graph. The blue line indicates patients with abnormal baseline PFTs ( $n=15$; five patients developed pulmonary disease 2-7 years after the PFTs). The yellow dashed line depicts patients with normal baseline PFT $(n=25$; two patients were diagnosed with symptomatic pulmonary disease at 2 and 10 years after the baseline PFTs). The cumulative incidence of pulmonary disease by age 20 years was $55 \%$ $(95 \% \mathrm{Cl} 28-100 \%)$ in patients with abnormal baseline PFT versus $17 \%(95 \% \mathrm{Cl} 3-100 \%)$ in those with normal PFTs (overall $p=0.02$ ). 

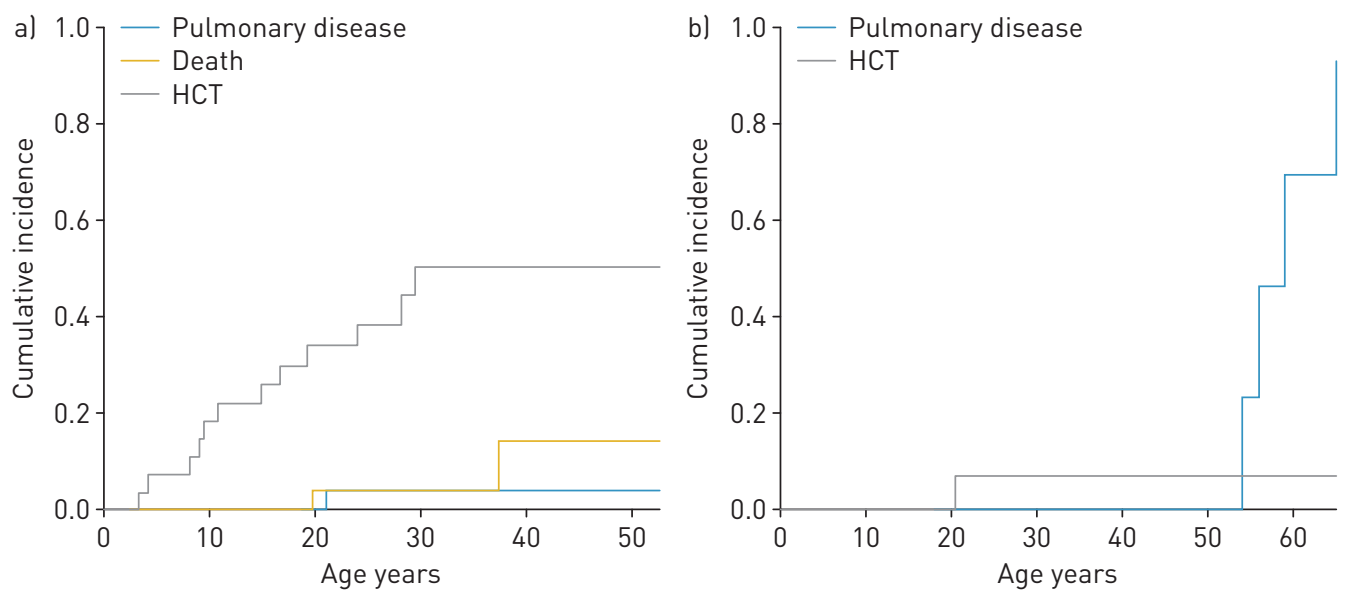

FIGURE 4 Competing risk of adverse events including pulmonary disease, haematopoietic cell transplantation (HCT), and death. a) autosomal recessive/X-linked recessive and TINF2 dyskeratosis congenita (DC). The first event was HCT for severe bone marrow failure in 12 patients (grey line) with a cumulative incidence of $50 \%(95 \%$ $\mathrm{Cl} 33-77 \%$ ) by age 30 years; two patients died at age 19 and 37 years from other causes (yellow line) and one developed pulmonary fibrosis plus pulmonary arteriovenous malformations at age 20 years (blue line). b) autosomal dominant non-TINF2 DC. In all, one patient received HCT, whereas four patients developed pulmonary fibrosis with a cumulative incidence of $70 \%(95 \% \mathrm{Cl} 39-100 \%)$ by age 60 years among non-HCT patients.

age 17 years and is alive with improvement in her pulmonary status. Another patient with PF (NCI-204-1) underwent successful bilateral lung transplantation at age 13 years, 2 years after the diagnosis of PF [16]. He died 6 years later, from metastatic squamous cell carcinoma of the tongue. In all, seven of 12 patients with symptomatic pulmonary disease have died at a median interval of 2.3 years (range 0.96-4.2) from the diagnosis of pulmonary disease. The rate of progression from the diagnosis of pulmonary disease to death (or lung transplant) appeared to be more rapid for patients who underwent HCT than those who did not have HCT (median interval 2.1 years, range 0.96-3.45 versus 4.19, respectively; $\mathrm{p}=0.007$ ). The median follow-up of the five patients living with pulmonary disease was 3.9 years (range 1.8-4.6) from the diagnosis of pulmonary disease.

\section{Discussion}

This study of baseline PFTs in patients with DC/TBD found that abnormalities were common even in the absence of overt pulmonary symptoms. Notably, both restrictive and obstructive changes on spirometry as well as reduced alveolar-capillary gas exchange were present in more than $40 \%$ of patients with DC. Baseline PFT abnormalities in patients with DC may signify early lung involvement due to their inherently high risk of PF $[29,30]$. Some patients with DC with pulmonary involvement may have PAVMs, with or without fibrosis, as previously reported $[17,18]$.

Restrictive changes on spirometry and moderate/severe impairment of alveolar-capillary gas exchange were significantly more common in patients with DC who developed pulmonary disease. Overall, 14 clinically unaffected relatives were heterozygous carriers of pathogenic variants in TERT, PARN and RTEL1, whereas their relatives had DC due to two pathogenic variants (AR disease). The PFTs in carrier and noncarrier relatives were similar, and neither group has developed pulmonary disease, to date. However, the carrier relatives in our study were young (median age of 46 years) and had not reached the age at which PF is generally reported [31]. In a recent study of 115 individuals with familial PF, the mean age of PF in heterozygous carriers of TERT variants was 58 years, RTEL1 was 60 years, and PARN was 65 years [31]. Prospective follow-up of the carrier relatives in our study is underway.

DC is a TBD with complex multisystem manifestations resulting in a clinically severe disease phenotype $[1,6,7,32-35]$. Most of our patients with XLR, AR, and TINF2 DC presented in infancy or childhood with complex phenotypes including $\mathrm{HH}$ and RS and had extremely short telomeres compared with patients with AD non-TINF2 DC. Although we found a similar frequency of baseline PFT abnormalities and severe BMF in patients with XLR, AR and TINF2 DC and in those with AD non-TINF2 DC, their ages at disease manifestations differed. Notably, abnormal PFTs were not highly correlated with other DC features, inheritance patterns or telomere length Z-scores, perhaps for the same reason.

Patients with clinically symptomatic PF had a rapidly progressive disease with a short survival regardless of the gene involved or whether PF developed after HCT. While we acknowledge that our study was limited by small numbers, potential confounding effects of HCT in patients with severe BMF, and lack of 
longitudinal PFT data, our findings were consistent with studies also reporting a rapid rate of decline in pulmonary function in patients with pathogenic variants in telomere biology genes, with a mean survival of $2-5$ years in clinically symptomatic patients $[31,36]$. The high incidence of PF in patients with DC after HCT is also consistent with prior reports $[16,37]$. Since HCT is the definitive treatment for BMF in these patients, nonmyeloablative radiation-free conditioning regimens are recommended to limit tissue injury to lungs $[38,39]$.

In summary, patients with DC often have asymptomatic PFT abnormalities that are associated with progression to PF occurring at young ages in patients with XLR, AR and TINF2 DC and after HCT. PFTs are an important part of the baseline evaluation for all patients with DC and related TBDs and should be performed at regular intervals. Patients and caregivers should be counselled to avoid smoking and medications associated with PF. Early referral to expert TBD clinicians and lung transplant centres is recommended if pulmonary symptoms develop. The frequent occurrence of PF in TBDs and its rapid progression after symptoms develop, highlight the urgent need for large, collaborative studies into the underlying mechanisms, prevention and development of therapeutics.

Acknowledgements: We are grateful to the patients and their families for the valuable contributions to the study. We would like to thank all the referring physicians, the pulmonary laboratory technologists and Lisa Leathwood, Maureen Risch and Ann Carr of Westat Inc. (Rockville, MD, USA) for excellent study support.

Conflict of interest: None declared.

Support statement: This work was supported by the Intramural Research Program of the Division of Cancer Epidemiology and Genetics, National Cancer Institute and by the Intramural Research Program of the National Heart, Lung and Blood Institute. Contract HHSN261201700004C with Westat, Inc. also supported this work. Funding information for this article has been deposited with the Crossref Funder Registry.

\section{References}

1 Bertuch AA. The molecular genetics of the telomere biology disorders. RNA Biol 2016; 13: 696-706.

2 Savage SA. Beginning at the ends: telomeres and human disease. F1000Res 2018; 7: F1000.

3 Alter BP, Giri N, Savage SA, et al. Cancer in the National Cancer Institute inherited bone marrow failure syndrome cohort after fifteen years of follow-up. Haematologica 2018; 103: 30-39.

4 Dokal I, Vulliamy T, Mason P, et al. Clinical utility gene card for: dyskeratosis congenita - update 2015. Eur J Hum Genet 2015; 23: https://doi.org/10.1038/ejhg.2014.170.

5 Vulliamy TJ, Marrone A, Knight SW, et al. Mutations in dyskeratosis congenita: their impact on telomere length and the diversity of clinical presentation. Blood 2006; 107: 2680-2685.

6 Glousker G, Touzot F, Revy P, et al. Unraveling the pathogenesis of Hoyeraal-Hreidarsson syndrome, a complex telomere biology disorder. Br J Haematol 2015; 170: 457-471.

7 Revesz T, Fletcher S, al-Gazali LI, et al. Bilateral retinopathy, aplastic anaemia, and central nervous system abnormalities: a new syndrome? J Med Genet 1992; 29: 673-675.

8 Armanios M. Telomeres and age-related disease: how telomere biology informs clinical paradigms. J Clin Invest 2013; 123: 996-1002.

9 Alter BP, Rosenberg PS, Giri N, et al. Telomere length is associated with disease severity and declines with age in dyskeratosis congenita. Haematologica 2012; 97: 353-359.

10 Armanios MY, Chen JJ, Cogan JD, et al. Telomerase mutations in families with idiopathic pulmonary fibrosis. N Engl J Med 2007; 356: 1317-1326.

11 Diaz de Leon A, Cronkhite JT, Katzenstein AL, et al. Telomere lengths, pulmonary fibrosis and telomerase (TERT) mutations. PLoS One 2010; 5: e10680.

12 Cronkhite JT, Xing C, Raghu G, et al. Telomere shortening in familial and sporadic pulmonary fibrosis. Am J Respir Crit Care Med 2008; 178: 729-737.

13 Stanley SE, Gable DL, Wagner CL, et al. Loss-of-function mutations in the RNA biogenesis factor NAF1 predispose to pulmonary fibrosis-emphysema. Sci Transl Med 2016; 8: 351ra107.

14 Stuart BD, Choi J, Zaidi S, et al. Exome sequencing links mutations in PARN and RTEL1 with familial pulmonary fibrosis and telomere shortening. Nat Genet 2015; 47: 512-517.

15 Lederer DJ, Martinez FJ. Idiopathic pulmonary fibrosis. N Engl J Med 2018; 378: 1811-1823.

16 Giri N, Lee R, Faro A, et al. Lung transplantation for pulmonary fibrosis in dyskeratosis congenita: case report and systematic literature review. BMC Blood Disord 2011; 11: 3.

17 Khincha PP, Bertuch AA, Agarwal S, et al. Pulmonary arteriovenous malformations: an uncharacterised phenotype of dyskeratosis congenita and related telomere biology disorders. Eur Respir J 2017; 49: 1601640.

18 Gorgy AI, Jonassaint NL, Stanley SE, et al. Hepatopulmonary syndrome is a frequent cause of dyspnea in the short telomere disorders. Chest 2015; 148: 1019-1026.

19 Alter BP, Giri N, Savage SA, et al. Malignancies and survival patterns in the National Cancer Institute inherited bone marrow failure syndromes cohort study. Br J Haematol 2010; 150: 179-188.

20 Vulliamy T, Dokal I. Dyskeratosis congenita. Semin Hematol 2006; 43: 157-166.

21 Alter BP, Baerlocher GM, Savage SA, et al. Very short telomere length by flow fluorescence in situ hybridization identifies patients with dyskeratosis congenita. Blood 2007; 110: 1439-1447.

22 Miller MR, Hankinson J, Brusasco V, et al. Standardisation of spirometry. Eur Respir J 2005; 26: 319-338.

23 Macintyre N, Crapo RO, Viegi G, et al. Standardisation of the single-breath determination of carbon monoxide uptake in the lung. Eur Respir J 2005; 26: 720-735.

24 Pellegrino R, Viegi G, Brusasco V, et al. Interpretative strategies for lung function tests. Eur Respir J 2005; 26 : 948-968. 
Gazzaniga P, Buscarini E, Leandro G, et al. Contrast echocardiography for pulmonary arteriovenous malformations screening: does any bubble matter? Eur J Echocardiogr 2009; 10: 513-518.

26 Ward SC, Savage SA, Giri N, et al. Beyond the triad: inheritance, mucocutaneous phenotype and mortality in a cohort of patients with dyskeratosis congenita. J Am Acad Dermatol 2018; 78: 804-806.

27 Garcia CK. Whole-exome sequencing insights into adult pulmonary fibrosis. Repeating the telomere theme. Am $J$ Respir Crit Care Med 2017; 196: 7-9.

28 Petrovski S, Todd JL, Durheim MT, et al. An exome sequencing study to assess the role of rare genetic variation in pulmonary fibrosis. Am J Respir Crit Care Med 2017; 196: 82-93.

29 Dokal I. Dyskeratosis congenita in all its forms. Br J Haematol 2000; 110: 768-779.

30 Calado RT. Telomeres in lung diseases. Prog Mol Biol Transl Sci 2014; 125: 173-183.

31 Newton CA, Batra K, Torrealba J, et al. Telomere-related lung fibrosis is diagnostically heterogeneous but uniformly progressive. Eur Respir J 2016; 48: 1710-1720.

32 Kirwan M, Dokal I. Dyskeratosis congenita: a genetic disorder of many faces. Clin Genet 2008; 73: 103-112.

33 Savage SA. Dyskeratosis congenita. In: Adam MP, Ardinger HH, Pagon RA, et al., eds. Gene Reviews. Seattle, University of Washington, 1993.

34 Yaghmai R, Kimyai-Asadi A, Rostamiani K, et al. Overlap of dyskeratosis congenita with the Hoyeraal-Hreidarsson syndrome. J Pediatr 2000; 136: 390-393.

35 Anderson BH, Kasher PR, Mayer J, et al. Mutations in CTC1, encoding conserved telomere maintenance component 1, cause coats plus. Nat Genet 2012; 44: 338-342.

36 Karimi-Shah BA, Chowdhury BA. Forced vital capacity in idiopathic pulmonary fibrosis - FDA review of pirfenidone and nintedanib. N Engl J Med 2015; 372: 1189-1191.

37 Barbaro P, Vedi A. Survival after hematopoietic stem cell transplant in patients with dyskeratosis congenita: systematic review of the literature. Biol Blood Marrow Transplant 2016; 22: 1152-1158.

38 Dietz AC, Orchard PJ, Baker KS, et al. Disease-specific hematopoietic cell transplantation: nonmyeloablative conditioning regimen for dyskeratosis congenita. Bone Marrow Transplant 2011; 46: 98-104.

39 Agarwal S. Evaluation and management of hematopoietic failure in dyskeratosis congenita. Hematol Oncol Clin North Am 2018; 32: 669-685. 